\title{
Cortical NR2B NMDA subunit antagonism reduces inflammatory pain in male and female rats
}

This article was published in the following Dove Press journal: Journal of Pain Research

23 September 2011

Number of times this article has been viewed

\author{
Gabriel C Quintero' \\ Jairo Herrera ${ }^{1,2}$ \\ José Bethancourt ${ }^{1}$ \\ 'Institute of Scientific Research \\ and High Technology Services \\ (INDICASAT-AIP), Center \\ for Neurosciences, Panama; \\ ${ }^{2}$ Academic Direction of Psychology, \\ Interamerican University of Panama, \\ Panama
}

Background: Studies have shown that $N$-methyl-D-aspartate (NMDA) receptors play a critical role in pain processing at different levels of the central nervous system.

Methods: In this study, we used adult Wistar rats to examine gender differences in the effects of NR2B NMDA antagonism at the level of the anterior cingulate cortex in phasic pain, and in the first and second phases of a formalin test. Rats underwent stereotactic surgery for cannula implantation in the anterior cingulate cortex. After recovery, paw withdrawal latency to a noxious thermal stimulus was assessed. Rats were also subjected to a formalin pain test whereby $60 \mu \mathrm{L}$ of $5 \%$ formalin was injected into the right hind paw.

Results: Female and male rats that received Ro 25-6981, an NR2B antagonist, before formalin injection showed significantly reduced pain responses to the formalin test compared with salineinjected control rats $(P<0.05)$. No gender differences in phasic pain responses were found in rats treated with Ro 25-6981.

Conclusion: These results suggest that cortical antagonism of the NR2B subunit reduces inflammatory pain levels in both genders of rat.

Keywords: cingulate cortex, NMDA receptor, NR2B protein, rats, gender

\section{Introduction}

$\mathrm{N}$-methyl-D-aspartate (NMDA) receptors from different areas in the central nervous system, including the anterior cingulate cortex, are fundamental in the generation of inflammatory pain responses. ${ }^{1}$ Tissues examined in previous studies have included the spinal cord, periaqueductal gray matter, and thalamus, and have concluded that NMDA receptor agonism generates an increase in the inflammatory pain response. ${ }^{2-6}$ In addition, one study has found that a decrease in the activation of NMDA receptors by means of genetic or pharmacologic manipulation generates a subsequent decrease in the inflammatory pain response.

Functional NMDA receptors are typically composed of heterogenic NR1, NR2A, NR2B, NR2C, NR2D, NR3A, and NR3B subunits. ${ }^{8,9}$ The NR2A and NR2B subunits are highly expressed in the frontal areas of the brain (including the anterior cingulate cortex) in rodents and humans. ${ }^{10}$ One previous study reported that NR2B subunit overexpression in the insular and anterior cingulate cortices tended to increase inflammatory pain without affecting phasic pain responses. These results suggest the potential role of the NR2B subunit at the forebrain level, especially the anterior cingulate cortex, as a possible strategy for the management of persistent pain conditions. ${ }^{10}$ Moreover, a study by $\mathrm{Wu}$ et al reported that peripheral inflammatory pain induces upregulation of NR2B receptors at the level of the anterior cingulate cortex, and antagonism of
Center for Neurosciences, INDICASAT-AIP, No. 219 Clayton, Ciudad del Saber, Panamá, Panamá Tel +l 5073979772

Fax + I 5073979772

Email gquintero2008@gmail.com 
these receptors reduces behavioral sensitization related to inflammation in a Freund's complete adjuvant model in male rodents. ${ }^{11}$

Participation of the anterior cingulate cortex and other cortical areas in persistent pain responses has been described before. In particular, the anterior cingulate cortex has been related to affective components of pain as well as the sensory part of pain and integrative features of pain (affectivecognition selection of response). ${ }^{12-17}$

The long-term potentiation process in the anterior cingulate cortex is proposed as the molecular mechanism underlying the sensitization of chronic pain conditions. The long-term potentiation mechanism involves mainly the excitatory neurotransmitter, glutamate, and its postsynaptic receptors, $\alpha$-amino-3-hydroxy-5-methyl-4-isoxazolepropionic acid (AMPA) and NMDA. ${ }^{1,17-19}$ In addition, some authors have proposed specific exploration of NR2B subunit antagonism at the level of the anterior cingulate cortex as a strategy for reducing persistent pain and side effects in contrast with other NMDA antagonists. ${ }^{10,20}$ Further studies have reported gender differences in mechanisms of pain and analgesia involving NMDA receptors. ${ }^{21-23}$ In general, the importance of including female groups and their reproductive cycle phases in pain research and in other fields of neurobiological research has been recognized. ${ }^{24-26}$

A previous study has demonstrated that Ro 25-6981 is a very selective antagonist and activity-dependent blocker of NMDA receptors containing the NR2B subunit. ${ }^{27}$ However, there have been few studies exploring gender differences in the role of the cortex in pain responses. The objective of the present study was to evaluate gender differences in the effects of anterior cingulate cortex NR2B receptor antagonism on phasic and tonic pain responses.

\section{Materials and methods Subjects}

A total of 86 adult male and female Wistar rats were used. The female rats weighed 200-225 g and the male rats weighed 275-300 g. Female rats performed their behavioral tests in the estrus phase of the estrous cycle. Breeding pairs of rats were obtained from Harlan Company (Mexico City, Mexico) and bred, housed, and maintained in the animal care facilities of the Instituto de Investigaciones Científicas Avanzadas y Servicios de Alta Tecnología, Asociación de Interés Público (INDICASAT-AIP) according to Public Health Service procedures. Animals were housed in light/ dark cycles of 14 hours $\times 10$ hours with water and food ad libitum. All the experiments adhered to the guidelines of the
Committee for Research and Ethical Issues of International Association for the Study of Pain. ${ }^{28}$ Moreover, the scientific work was reviewed by the scientific committee of the INDICASAT-AIP.

\section{Stereotactic surgery and infusion}

The animals were anesthetized with an intramuscular injection of ketamine $75 \mathrm{mg} / \mathrm{kg}$ + xylazine $10 \mathrm{mg} / \mathrm{kg}$. Surgery was carried out using stereotactic apparatus. For microinfusion experiments, chronic guide cannulae were implanted according to the following procedure: double stainless steel guide cannulae (26GA, Plastics One Inc, Roanoke, VA) were implanted $1 \mathrm{~mm}$ over the anterior cingulate cortex injection site $(\mathrm{AP}+2.6$, $\mathrm{D} / \mathrm{V}-1.6, \mathrm{M} / \mathrm{L} \pm 0.6$, Bregma). After chronic guide cannula implantation, the holes were closed with dummy cannulae of the same extension ( $0.2 \mathrm{~mm}$, Plastics One Inc). One week later, the rats were administered either Ro 25-6981 (Sigma, St Louis, MO) or saline infusions through injector cannulae (33GA, Plastics One Inc) connected to tubing (PE 20, Plastics One Inc) and a Hamilton syringe (Model 7001 Gas Tight, Harvard Apparatus, Holliston, MA). All animals included in the study recovered adequately from surgery, as verified by post-surgery weight measurements.

\section{Drug preparation}

Ro 25-6981, an antagonist of the NR2B subunit of the NMDA receptor, was prepared in sterilized isotonic saline solution $(0.9 \% \mathrm{NaCl})$. The drug was prepared at a $1 \mu \mathrm{g} / 0.5 \mu \mathrm{L}$ concentration and administered at a rate of $0.5 \mu \mathrm{L} / 90$ seconds for a total volume of $0.5 \mu \mathrm{L}$ per side. ${ }^{29}$ The drug or vehicle (isotonic saline) was administered through a cannula system connected to PE 20 tubing and a Hamilton syringe.

\section{Behavioral testing and drug delivery}

All the behavioral testing was performed by evaluators blinded to the drug treatment administered. In each test, the rats had been habituated beforehand to the behavioral apparatus (Hargreaves or formalin cages) for 40 minutes on three consecutive days. ${ }^{7}$ Rats were handled by the investigator before the test on the same days of apparatus habituation. Behavioral experiments were performed during light-cycle hours; furthermore, all the animals were behaviorally assessed in groups of at least 2-4 rats to avoid any effects of isolation analgesia. The injector cannulae were left for a period of 20-30 seconds before injection of the drug or the saline control, and were left for a period of two minutes after injection of the drug. For the Hargreaves experiments, behavioral measurements (latencies) were 
recorded at five minutes for the control and experimental groups and at 30 minutes for the experimental groups after drug or saline injection. For the formalin test, drug or saline infusion was performed 15 minutes before and 25 minutes after formalin injection.

\section{Hargreaves test}

For the Hargreaves test, the experimental groups used were: male controls without surgery $(n=8)$, female controls without surgery $(n=8)$, males that received saline infusion $(n=7)$, females that received saline infusion $(n=6)$, males that received Ro 25-6981 infusion $(n=7)$, and females that received Ro 25-6981 infusion $(n=7)$. After cerebral infusion of the drug or vehicle, phasic pain responses were assessed using the Hargreaves test at five and 30 minutes after infusion. ${ }^{30}$ Rats were placed in the Plexiglas compartments $(12 \mathrm{~cm}$ height $\times 21 \mathrm{~cm}$ length $\times 10 \mathrm{~cm}$ width) of an analgesiometer apparatus (IITC Life Sciences, Woodland Hills, CA). A heat source was applied to the plantar surface, and the paw withdrawal latency of each hind paw was measured at 2-5 minute intervals (one latency for each hind paw). A cutoff time of 15 seconds was established for avoiding tissue damage. An average value was calculated for each rat.

\section{Formalin test}

The experimental groups used for the formalin test comprised males that received saline infusion before formalin injection $(n=10)$, females that received saline infusion before formalin injection $(n=6)$, males that received Ro 25-6981 infusion before formalin injection $(n=7)$, females that received Ro 25-6981 infusion before formalin injection $(n=7)$, males that received Ro 25-6981 infusion after formalin injection $(\mathrm{n}=8)$, and females that received Ro 25-6981 infusion after formalin injection $(n=5)$. The formalin test was used as a model of the tonic response to inflammatory pain. ${ }^{31-34}$ This test was performed 72 hours after the Hargreaves test. Rats were injected subcutaneously into the plantar surface of the right hind paw with $60 \mu \mathrm{L}$ of $5 \%$ formalin. Cerebral infusions of the drug or saline were carried out 15 minutes before and 25 minutes after formalin injection. Following formalin injection, the behavior of the rats was recorded using a digital video camera for a period of 60 minutes. Licking and/or biting of the injected hind paw was considered as an index of pain-related behavior; this behavior was recorded and quantified in seconds during time blocks of five minutes by two independent and blinded evaluators. Later, for each block of five minutes, the average score of the two evaluators was calculated.

\section{Cannula verification}

After finishing the behavioral experiments, rats were administered a lethal dose of ketamine/xylazine and received a bilateral infusion of $0.025 \%$ methylene blue in the anterior cingulate cortex. Immediately after this, the rats were perfused with isotonic saline solution $(0.9 \%$ $\mathrm{NaCl}$ ) via cardiac puncture followed by $4 \%$ formaldehyde solution. The brains were then extracted and processed as described elsewhere ${ }^{29}$ and analyzed further under a light microscope. Only rats with exact cannula location in the anterior cingulate cortex were included in this investigation. The samples included in the accompanying figures describe the number of animals that passed the cannula verification procedure satisfactorily. Drawings of the histology are presented in the additional material in Supplementary Figure 1.

\section{Statistical analysis}

Statistical analysis was performed using analysis of variance with post hoc tests. Statistical significance was set at $P<0.05$. SPSS version 19 for Windows (SSPS Inc, Chicago, IL) was used for the statistical analysis.

\section{Results}

\section{No effects of Ro 25-698I on phasic pain responses}

The Hargreaves test was used to determine if infusion of Ro 25-6981 into the anterior cingulate cortex could reduce phasic pain levels in rats of both genders and to exclude possible motor deficits due to stereotactic surgery. There were no significant differences between the experimental groups for mean paw withdrawal latency based on repeated-measures analysis of variance, ie, time effect (Wilk's $\lambda=0.97, \mathrm{~F}[1,23]=0.82$, $P=0.38$ ), gender effect (Wilk's $\lambda=1, \mathrm{~F}[1,23]=0.02$, $P=0.96$ ), treatment effect (Wilk's $\lambda=1, \mathrm{~F}[1,23]=0.08$, $P=0.79)$, or interaction effect, ie, time $\times$ gender $\times$ treatment (Wilk's $\lambda=0.97, \mathrm{~F}[1,23]=0.63, P=0.43$ ). Moreover, comparing rats that received saline using analysis of variance did not find any gender or treatment effects (see Figure 1). This lack of difference suggests that stereotactic surgery did not induce any secondary or side effects in motor response (that otherwise could have been manifested as differences in latency).

\section{Effect of Ro 25-698I on first and second phases of the formalin test}

A formalin test was used to evaluate possible gender differences in the effects of Ro 25-6981 on the first and second 


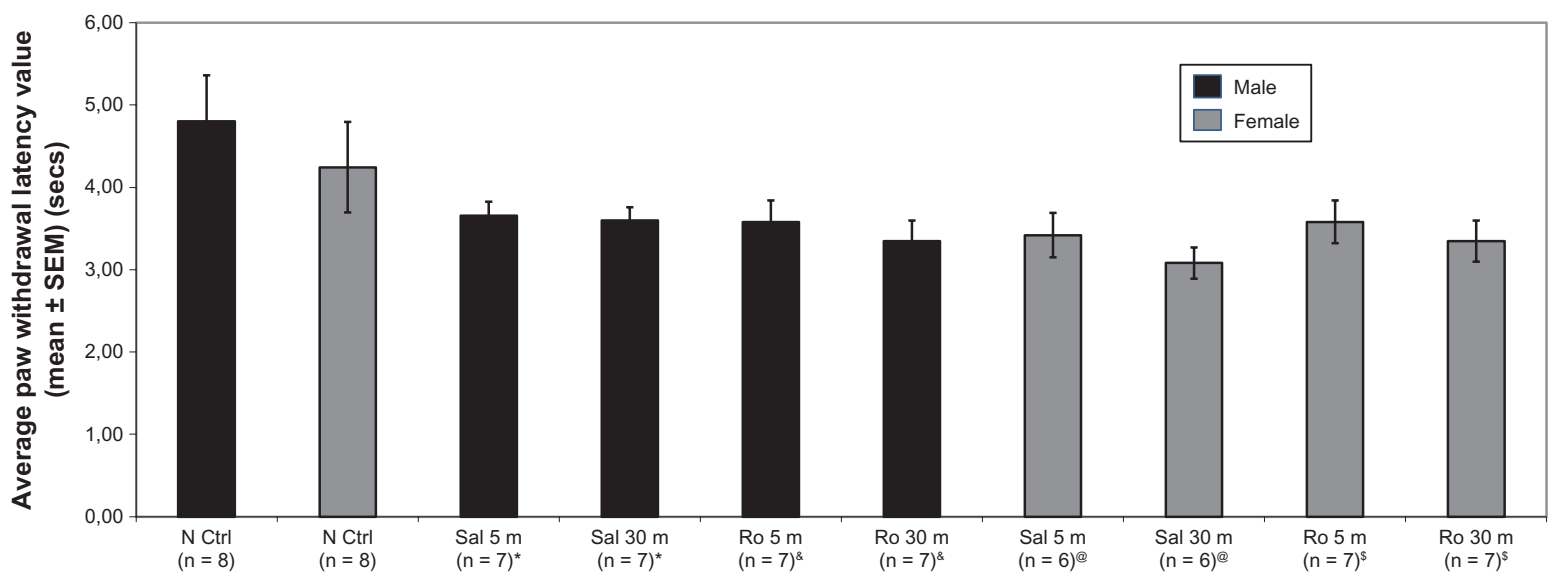

Figure I Chart showing mean values of paw withdrawal latency in different groups of rats in the Hargreaves test. The paw withdrawal latency to thermal stimulus was measured in normal control rats, rats that received saline (vehicle) and rats that received Ro 25-698I.

Notes: Data are expressed as mean time ( \pm standard error of the mean) in seconds of paw withdrawal latency after application of a heat stimulus to the hind paw. Repeated measures analysis of variance comparing rats that received saline and Ro 25-698I did not find a time, gender, treatment, or interaction effect. Moreover, analysis of variance comparing rats that receive saline and control did not find gender nor treatment effects ( $P=$ not significant). *, \&, @, \$ means that the same animals were used for both time points (five minutes and 30 minutes).

Abbreviations: N Ctrl, naive control; Sal 5 m, saline applied at five minutes; Sal 30 m, saline applied at 30 minutes; Ro 5 m, Ro $25-698 \mathrm{I}$ applied at five minutes; Ro 30 m, Ro 25-698I applied at 30 minutes; SEM, standard error of the mean; PWL, paw withdrawal latency

phases of the formalin test at different time points (infused before or after formalin injection). Gender comparisons of tonic pain responses when the drug was infused before formalin injection (0-10 minutes and 10-20 minutes in Figure 2) did not show any differences between males and females (Wilk's $\lambda=0.998, \mathrm{~F}[1,31]=0.055, P>0.05$ ). However, a gender difference in tonic pain response was seen when the drug was infused (30-40 minutes and 40-50 minutes in Figure 2) after formalin injection (Wilk's $\lambda=0.868$, $\mathrm{F}[1,33]=5.037, P<0.05)$. Specifically, male rats that received the drug displayed fewer pain-related behaviors than female rats that received drug.

On the other hand, male rats that received the drug before formalin injection showed significantly fewer pain-related behaviors compared with male rats that received saline at $0-10$ minutes and 10-20 minutes after formalin injection, according to analysis of variance (Wilk's $\lambda=0.39$, $\mathrm{F}[2,11]=8.63, P<0.05)$. Female rats that received the drug before formalin injection also showed fewer pain-related behaviors compared with female rats that received saline at $0-10$ minutes, according to analysis of variance (Wilk's $\lambda=0.431, \mathrm{~F}[2,7]=4.62, P<0.05$, see Figure 2).

Male rats that received the drug infusion after the formalin injection also displayed fewer pain-related behaviors compared with male rats that received the saline infusion at 30-40 minutes, based on analysis of variance (Wilk's $\lambda=0.527, \mathrm{~F}[4,38]=3.59, P<0.05$; post hoc test, $P<0.05$ ). Moreover, male rats that received the drug before the formalin injection still displayed fewer pain-related behaviors compared with rats that received saline at 30-40 minutes
(Wilk's $\lambda=0.527, \mathrm{~F}[4,38]=3.59, P<0.05$; post hoc test, $P<0.05$, see Figure 2). Female rats that received the drug after the formalin injection also showed fewer pain-related behaviors compared with rats that received saline, but this difference did not reach statistical significance. In general, both male and female rats that received the drug before the formalin injection showed lower levels of inflammatory pain compared with those that received saline. Moreover, male rats that received the drug after the formalin injection showed fewer pain-related behaviors compared with their salinetreated counterparts; however, female rats that received the drug after formalin injection showed fewer pain-related behaviors compared with female rats that received saline, but this tendency was not statistically significant.

\section{Discussion}

In this study, we found that Ro 25-6981 infusion was able to reduce formalin-induced pain-related behavior in both genders without affecting phasic pain responses. This study demonstrates that the analgesic action of NR2B antagonism (Ro 25-6981) applied at the level of the anterior cingulate cortex was able to reduce inflammatory pain levels in both male and female rats. A previous study by Wu et al reported a relationship between upregulation of NR2B receptors at the level of the anterior cingulate cortex and behavioral sensitization to inflammation in rodents, and that antagonism of NR2B in the anterior cingulate cortex reduced this sensitization. ${ }^{11}$ However, gender differences have not been explored in the context of antagonism of NR2B at the level of the anterior cingulate cortex. In the present study, a 


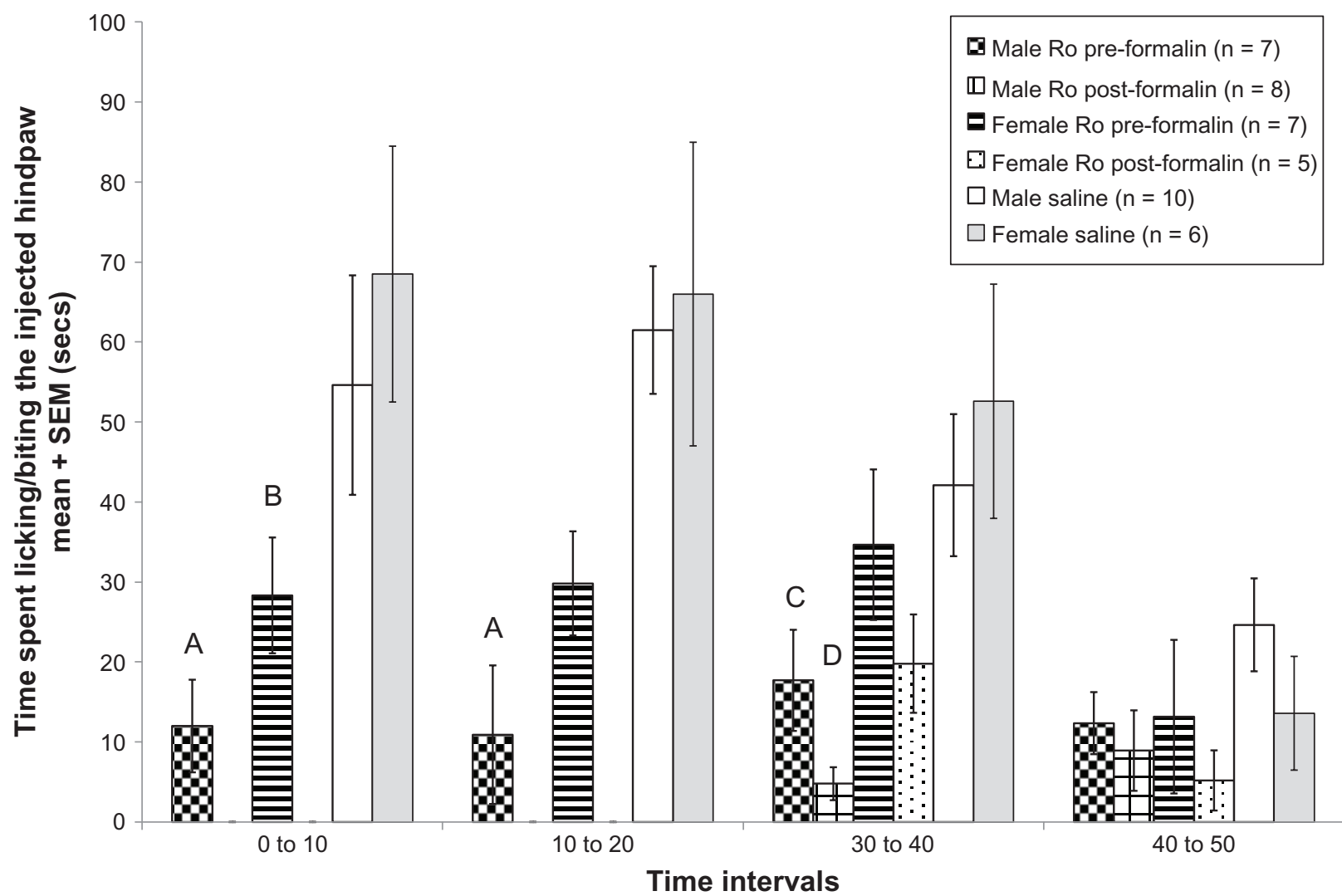

Figure 2 Average paw biting/licking values of different rat groups across different treatments in the formalin test. Data are expressed as mean ( \pm standard error of the mean) time in seconds spent licking/biting the hind paw after injection of $5 \%$ formalin $60 \mu \mathrm{L}$. Significant differences were found between male rats that received Ro $25-698$ I before formalin injection and male rats that received saline $(\mathbf{A})$ at $0-10$ minutes and $10-20$ minutes $(P<0.05)$. Moreover, significant differences were also found between female rats that received Ro 25-698। before formalin injection and female rats that received saline $(\mathbf{B})$ at $0-10$ minutes $(P<0.05)$. Significant differences were also found between male rats that received Ro 25-698I before formalin injection and male rats that received saline $(\mathbf{C})$ at 30-40 minutes $(P<0.05)$, and between male rats that received Ro $25-698$ I after formalin injection and male rats that received saline $(D)$ at $30-40$ minutes $(P<0.05)$. All analyses were performed using analysis of variance tests.

Abbreviations: Male Ro pre-formalin, male rats that received Ro 25-698I before formalin injection; male Ro post-formalin: male rats that received Ro 25-698I after formalin injection; female Ro pre-formalin, female rats that received Ro 25-698I before formalin injection; female Ro post-formalin, female rats that received Ro 25-698। after formalin injection; male saline, male rats that received saline; female saline, female rats that received saline.

significant reduction in inflammatory pain was found if the drug was applied before formalin injection in both males and females, indicating no gender differences in the effects of the drug on the inflammatory pain response when Ro 25-6981 is applied before formalin injection. However, the drug had a stronger analgesic effect in males than in females when administered after formalin injection. A possible explanation for this difference could be the estrogen hormone levels in female rodents; we used female rats in the estrus phase with a relatively high level of estrogen, and it has been shown that levels of estrogen and estrogen receptors (ER $\alpha$ and ER $\beta$ ) can modulate pain-related behavior in female rodents in response to the formalin test. ${ }^{35-37}$

Other studies by Bereiter et al and Takeshita et al have shown that estrogen levels can modulate temporomandibular joint pain in animals and humans at the lower brainstem level, and also that estrogen levels affect morphine modulation of temporomandibular joint unit activity. ${ }^{38,39}$ Another study by Bereiter et al has shown that estrogen status could affect glutamatergic neurotransmission in the temporomandibular joint region by modulation of glutamate reuptake, and this could contribute to differences in pain response between males and females. ${ }^{40}$

We did not find any treatment or gender difference among the experimental groups tested with the phasic pain model (Hargreaves test), suggesting that NMDA antagonism at the anterior cingulate cortex level does not influence phasic responses in either gender. Our results also suggest that there were no adverse effects of stereotactic surgery on motor coordination, because rats that received saline did not differ from the control rats in their latency response to thermal stimulation. The phasic test for exploring side effects on motor coordination processes has also been used previously. ${ }^{3}$

The results of the present study are consistent with those of previous studies, ie, infusion of Ro 25-6981 in the anterior cingulate cortex is able to reduce tonic pain levels in male rodents. Wu et al have previously shown this in a complete adjuvant pain model, but add that antagonism of the anterior 
cingulate cortex NR2B receptors is also able to reduce inflammatory pain in female rodents. ${ }^{11}$ Moreover, like our present results, the research by $\mathrm{Wu}$ et al reported a lack of effect of Ro 25-6981 infusion in the anterior cingulate cortex on male phasic responses. Our study further demonstrated an absence of effect of Ro 25-6981 on phasic pain responses in females.

Our results are also in accord with other research using intracisternal administration of Ro 25-6981 in an orofacial formalin pain model (injection of formalin in the vibrissae), ${ }^{41}$ which essentially showed reduction of tonic pain without side effects. ${ }^{41}$ The present results are also in agreement with the reduction of inflammatory pain levels and intact phasic pain response in neuropathic pain seen after electrolytic lesion of the anterior cingulate cortex. ${ }^{42}$

Furthermore, our study did not find marked gender differences in the effects of cortical administration of Ro 25-6981 in inflammatory pain if applied prior to formalin injection. However, when Ro 25-6981 was applied after formalin injection, it had a stronger analgesic effect in males than in females.

The present results differ from those of another study showing, in particular, an absence of effects of another NMDA antagonist (AP5) on inflammatory pain levels after administration in the anterior cingulate cortex. ${ }^{43}$ In contrast, we found that administration of a NR2B antagonist before formalin injection reduced pain intensity. Differences in our results from those in the study of AP5 cortical administration could be explained by differences in the selectivity of the NMDA antagonist used, the study samples used, and the method used for behavior analysis (eg, automated recording versus scoring of licking/biting). ${ }^{43}$

The present study did not find any gender differences in the effects of Ro 25-6981 on phasic pain responses at the cortical level. Other studies that have explored the effects of Ro 25-6981 on phasic pain responses in male (but not female) rats have not found effects of Ro 25-6981 on the hot plate test (another test of phasic pain). ${ }^{44}$ Moreover, a further study found that Ro 25-6981 potentiated morphine analgesia in mice of both genders in a phasic pain model (tail flick test). ${ }^{45}$ It seems that Ro 25-6981 does not induce gender differences in phasic pain responses even when combined with other drugs.

In terms of connectivity, the possible circuit involved in the inhibitory effects of Ro 25-6981 on tonic pain found in this study could lie in the corticoreticular and corticoventromedullar pathways that have synapses at the dorsal horn levels of the spinal cord, and reduce pain input from the spinal cord. ${ }^{46,47}$ Indeed, studies on anterior cingulate cortex inhibition of visceral pain suggest that the anterior cingulate cortex could mediate inhibition or enhancement of spinal nociception via the dorsal reticular nucleus and rostral ventral medulla. ${ }^{48}$

Some investigators consider phosphorylation of the NR2B subunit to be responsible for induction and continuation of the sensitization process seen in neuropathic pain conditions, so future studies could explore antagonism of the NR2B subunit at the anterior cingulate cortex level in other models of chronic pain, such as cancer pain, low back pain, and other newer models like chronic inflammatory joint pain. ${ }^{1,49,50}$ The novel contribution of this work is that it demonstrates the lack of a gender difference in antagonism of the NR2B subunit at the level of the anterior cingulate cortex with regard to the response to phasic pain, but does uncover some gender differences in the tonic inflammatory pain response. A limitation of this study was the use of females in the estrus phase only. In conclusion, our study found that antagonism of the NR2B subunit at the level of the anterior cingulate cortex can reduce inflammatory pain levels without affecting phasic pain responses or motor responses in both female and male rats.

\section{Acknowledgments}

This study was supported by SENACYT (Secretaría Nacional de Ciencia, Tecnología e Innovación de Panamá), PRB08-002 awarded to GQ. Also, grant INF08-017 from SENACYT was awarded to G Britton and G Quintero helping to buy equipment. We thank Dr KS Jagannatha Rao and Dr Gabrielle Britton for revision of the text. We also thank Dr Robert Beatty and his team from Sustainable Sciences Institute (SSI) for their revision and input to the manuscript, and INDICASAT (Instituto de Investigaciones Científicas y Servicios de Alta Tecnología) for use of its animal colony facilities.

\section{Disclosure}

The authors report no conflicts of interest in this work.

\section{References}

1. Wu LJ, Zhuo M. Targeting the NMDA receptor subunit NR2B for the treatment of neuropathic pain. Neurotherapeutics. 2009;6(4):693-702.

2. Coderre TJ, Melzack R. The role of NMDA receptor-operated calcium channels in persistent nociception after formalin-induced tissue injury. J Neurosci. 1992;12(9):3671-3675.

3. Vaccarino AL, Clemmons HR, Mader GJ Jr, Magnusson JE. A role of periaqueductal grey NMDA receptors in mediating formalin-induced pain in the rat. Neurosci Lett. 1997;236(2):117-119.

4. South SM, Kohno T, Kaspar BK, et al. A conditional deletion of the NR1 subunit of the NMDA receptor in adult spinal cord dorsal horn reduces NMDA currents and injury-induced pain. $J$ Neurosci. 2003;23(12):5031-5040. 
5. Eaton SA, Salt TE. Thalamic NMDA receptors and nociceptive sensory synaptic transmission. Neurosci Lett. 1990;110(3):297-302.

6. Kolhekar R, Murphy S, Gebhart GF. Thalamic NMDA receptors modulate inflammation-produced hyperalgesia in the rat. Pain. 1997;71(1):31-40.

7. Quintero GC, Erzurumlu RS, Vaccarino AL. Decreased pain response in mice following cortex-specific knockout of the N-methyl-D-aspartate NR1 subunit. Neurosci Lett. 2007;425(2):89-93.

8. Hollmann M, Heinemann S. Cloned glutamate receptors. Annu Rev Neurosci. 1994;17:31-108.

9. Dingledine R, Borges K, Bowie D, Traynelis SF. The glutamate receptor ion channels. Pharmacol Rev. 1999;51(1):7-61.

10. Wei F, Wang GD, Kerchner GA, et al. Genetic enhancement of inflammatory pain by forebrain NR2B overexpression. Nat Neurosci. 2001;4(2):164-169.

11. Wu LJ, Toyoda H, Zhao MG, et al. Upregulation of forebrain NMDA NR2B receptors contributes to behavioral sensitization after inflammation. J Neurosci. 2005;25(48):11107-11116.

12. Corkin SH, N. Subjective estimates of chronic pain before and after psychosurgery treatment in a pain unit. Pain. 1981;1:150.

13. de Leeuw R, Albuquerque R, Okeson J, Carlson C. The contribution of neuroimaging techniques to the understanding of supraspinal pain circuits: implications for orofacial pain. Oral Surg Oral Med Oral Pathol Oral Radiol Endod. 2005;100(3):308-314.

14. Ploner M, Schnitzler A. Cortical representation of pain. Nervenarzt. 2004;75(10):962-969. German.

15. Shibasaki H. Central mechanisms of pain perception. Suppl Clin Neurophysiol. 2004;57:39-49.

16. Talbot JD, Villemure JG, Bushnell MC, Duncan GH. Evaluation of pain perception after anterior capsulotomy: a case report. Somatosens Mot Res. 1995;12(2):115-126.

17. Zhuo M. A synaptic model for pain: long-term potentiation in the anterior cingulate cortex. Mol Cells. 2007;23(3):259-271.

18. Zhuo M. Molecular mechanisms of pain in the anterior cingulate cortex. J Neurosci Res. 2006;84(5):927-933.

19. Lujan-Miras R. Metabotropic glutamate receptors: new molecular targets in the treatment of neurological and psychiatric diseases. Rev Neurol. 2005;40(1):43-53. Spanish.

20. Boyce S, Wyatt A, Webb JK, et al. Selective NMDA NR2B antagonists induce antinociception without motor dysfunction: correlation with restricted localisation of NR2B subunit in dorsal horn. Neuropharmacology. 1999;38(5):611-623.

21. Kavaliers M, Choleris E. Sex differences in N-methyl-D-aspartate involvement in kappa opioid and non-opioid predator-induced analgesia in mice. Brain Res. 1997;768(1-2):30-36.

22. Vaccarino AL, Marek P, Sternberg W, Liebeskind JC. NMDA receptor antagonist MK-801 blocks non-opioid stress-induced analgesia in the formalin test. Pain. 1992;50(1):119-123.

23. Mogil JS, Sternberg WF, Kest B, Marek P, Liebeskind JC. Sex differences in the antagonism of swim stress-induced analgesia: effects of gonadectomy and estrogen replacement. Pain. 1993;53(1):17-25.

24. Becker JB, Arnold AP, Berkley KJ, et al. Strategies and methods for research on gender differences in brain and behavior. Endocrinology. 2005;146(4):1650-1673.

25. Mogil JS, Chanda ML. The case for the inclusion of female subjects in basic science studies of pain. Pain. 2005;117(1-2):1-5.

26. Mogil JS, Davis KD, Derbyshire SW. The necessity of animal models in pain research. Pain. 2010;151(1):12-17.

27. Fischer G, Mutel V, Trube G, et al. Ro 25-6981, a highly potent and selective blocker of N-methyl-D-aspartate receptors containing the NR2B subunit. Characterization in vitro. J Pharmacol Exp Ther. 1997;283(3):1285-1292.

28. Zimmermann M. Ethical guidelines for investigations of experimental pain in conscious animals. Pain. 1983;16(2):109-110

29. Johansen JP, Fields HL. Glutamatergic activation of anterior cingulate cortex produces an aversive teaching signal. Nat Neurosci. 2004;7(4):398-403.
30. Hargreaves K, Dubner R, Brown F, Flores C, Joris J. A new and sensitive method for measuring thermal nociception in cutaneous hyperalgesia. Pain. 1988;32(1):77-88.

31. Alreja M, Mutalik P, Nayar U, Manchanda SK. The formalin test: a tonic pain model in the primate. Pain. 1984;20(1):97-105.

32. Dubuisson D, Dennis SG. The formalin test: a quantitative study of the analgesic effects of morphine, meperidine, and brain stem stimulation in rats and cats. Pain. 1977;4(2):161-174.

33. Hunskaar S, Fasmer OB, Hole K. Formalin test in mice, a useful technique for evaluating mild analgesics. $J$ Neurosci Methods. 1985;14(1):69-76.

34. Lee IO, Jeong YS. Effects of different concentrations of formalin on paw edema and pain behaviors in rats. J Korean Med Sci. 2002;17(1):81-85.

35. Kuba T, Wu HB, Nazarian A, et al. Estradiol and progesterone differentially regulate formalin-induced nociception in ovariectomized female rats. Horm Behav. 2006;49(4):441-449.

36. Mannino CA, South SM, Quinones-Jenab V, Inturrisi CE. Estradiol replacement in ovariectomized rats is antihyperalgesic in the formalin test. J Pain. 2007;8(4):334-342.

37. Coulombe MA, Spooner MF, Gaumond I, Carrier JC, Marchand S. Estrogen receptors beta and alpha have specific pro- and anti-nociceptive actions. Neuroscience. 2011;184:172-182.

38. Bereiter DA, Okamoto K. Neurobiology of estrogen status in deep craniofacial pain. Int Rev Neurobiol. 2011;97:251-284.

39. Takeshita $\mathrm{S}$, Hirata $\mathrm{H}$, Bereiter DA. Intensity coding by TMJ-responsive neurons in superficial laminae of caudal medullary dorsal horn of the rat. J Neurophysiol. 2001;86(5):2393-2404.

40. Bereiter DA, Benetti AP. Amino acid release at the spinomedullary junction after inflammation of the TMJ region in male and female rats. Pain. 2006;126(1-3):175-183.

41. Yang GY, Woo YW, Park MK, Bae YC, Ahn DK, Bonfa E. Intracisternal administration of NR2 antagonists attenuates facial formalin-induced nociceptive behavior in rats. J Orofac Pain. 2010;24(2):203-211.

42. Donahue RR, LaGraize SC, Fuchs PN. Electrolytic lesion of the anterior cingulate cortex decreases inflammatory, but not neuropathic nociceptive behavior in rats. Brain Res. 2001;897(1-2):131-138.

43. Lei LG, Sun S, Gao YJ, Zhao ZQ, Zhang YQ. NMDA receptors in the anterior cingulate cortex mediate pain-related aversion. Exp Neurol. 2004;189(2):413-421.

44. Mathur P, Graybeal C, Feyder M, Davis MI, Holmes A. Fear memory impairing effects of systemic treatment with the NMDA NR2B subunit antagonist, Ro 25-6981, in mice: attenuation with ageing. Pharmacol Biochem Behav. 2009;91(3):453-460.

45. Nemmani KV, Grisel JE, Stowe JR, Smith-Carliss R, Mogil JS. Modulation of morphine analgesia by site-specific N-methyl-D-aspartate receptor antagonists: dependence on gender, site of antagonism, morphine dose, and time. Pain. 2004;109(3):274-283.

46. Calejesan AA, Kim SJ, Zhuo M. Descending facilitatory modulation of a behavioral nociceptive response by stimulation in the adult rat anterior cingulate cortex. Eur J Pain. 2000;4(1):83-96.

47. Zhang L, Zhang Y, Zhao ZQ. Anterior cingulate cortex contributes to the descending facilitatory modulation of pain via dorsal reticular nucleus. Eur J Neurosci. 2005;22(5):1141-1148.

48. Wu X, Gao J, Yan J, Fan J, Owyang C, Li Y. Role for NMDA receptors in visceral nociceptive transmission in the anterior cingulate cortex of viscerally hypersensitive rats. Am J Physiol Gastrointest Liver Physiol. 2008;294(4):G918-G927.

49. Gogas KR. Glutamate-based therapeutic approaches: NR2B receptor antagonists. Curr Opin Pharmacol. 2006;6(1):68-74.

50. Wilson AW, Medhurst SJ, Dixon CI, et al. An animal model of chronic inflammatory pain: pharmacological and temporal differentiation from acute models. Eur J Pain. 2006;10(6):537-549. 


\section{Supplementary figure}
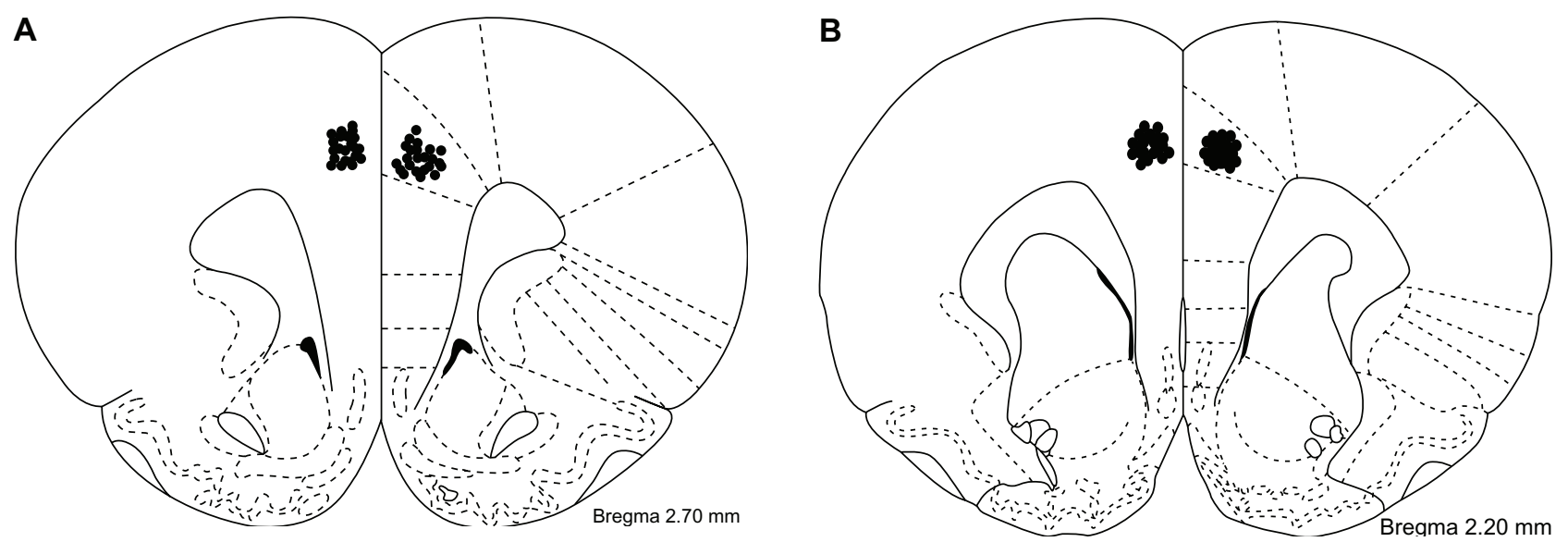

Figure SI (A) Injection sites (circles) for drug or vehicle infusion in the anterior cingulate cortex. (B) Injection sites (circles) for drug or vehicle infusion in the anterior cingulate cortex.

\section{Publish your work in this journal}

The Journal of Pain Research is an international, peer-reviewed, open access, online journal that welcomes laboratory and clinical findings in the fields of pain research and the prevention and management of pain. Original research, reviews, symposium reports, hypothesis formation and commentaries are all considered for publication.
The manuscript management system is completely online and includes a very quick and fair peer-review system, which is all easy to use. Visit http://www.dovepress.com/testimonials.php to read real quotes from published authors. 